\title{
A Review of the Essential Components of Quality Palliative Care in the Home
}

\author{
Hsien Seow, $\mathrm{PhD}^{1-3}$ and Daryl Bainbridge, $\mathrm{PhD}^{1,3}$
}

\begin{abstract}
Objective: The home is an important and often preferable setting of palliative care. While much research has demonstrated the benefits of specialized palliative homecare on patient and system outcomes, there has been little delineation of the underlying components of these efficacious programs. We synthesized the essential elements of palliative homecare from a combined review of successful programs, perspectives of patients and caregivers, and views of healthcare providers in palliative care.

Methods: Five unique palliative homecare studies were included in the rapid review and synthesis-(1) systematic review of the components of efficacious programs; (2) in-depth analysis of 11 effective communitybased teams; (3) survey of bereaved caregivers; (4) survey of the general public; and (5) interviews of providers and administrators. A qualitative approach was used to identify transcending themes across the studies.

Results: Six essential elements of quality palliative homecare were common across the studies: (1) Integrated teamwork; (2) Management of pain and physical symptoms; (3) Holistic care; (4) Caring, compassionate, and skilled providers; (5) Timely and responsive care; and (6) Patient and family preparedness.

Conclusions: Our metasynthesis of effective palliative homecare models, as well as, the values of those who use and provide these services, illuminates the underpinning elements of quality home-based care for patients with a life-limiting illness. However, the application of these elements must be relevant to the local community context. To create impactful, sustainable homecare programs, it is critical to capitalize on existing processes, partnerships, and assets.
\end{abstract}

Keywords: homecare; integration; interprofessional teams; palliative care; qualitative research

\section{Introduction}

$\mathbf{T}$ HE HOME IS AN IMPORTANT SETTING for palliative care because this is where most people with a life-limiting illness want to be cared for and die. ${ }^{1}$ Moreover, hospital care is costly and usually not optimal for the individual and the family at end of life. ${ }^{2,3}$ Homecare includes healthcare services (e.g., nursing, physiotherapy, and occupational therapy), practical services (e.g., personal support with activities of daily living), and equipment services, provided in the patient's place of residence. ${ }^{4}$ In Canada, the United States, and elsewhere, palliative or hospice homecare is a special designation of service that usually involves multiprofessional providers with specialized training and has a clear end-of-life intent. ${ }^{4-7}$

A large body of research has evaluated the outcomes of community-based palliative care, including services in the home. Three relevant systematic reviews identified nine randomized controlled trials, among other types of studies. ${ }^{8-10}$ Results consistently report improved symptom management, satisfaction, and/or quality of life, ${ }^{11-17}$ along with mixed evidence for lowering utilization and costs. ${ }^{13,14,17}$ For example, three trials demonstrated cost-savings of $47 \%$, $33 \%$, and $£ 1,798$ per person, respectively, compared with the usual care group. ${ }^{13,14,18}$ Observational studies on specialized palliative homecare have shown similar positive outcomes compared with generalist homecare. ${ }^{19-25}$ Within these randomized trials and observational studies, there was variation in the intervention components and compliment of providers that comprised the teams.

Much research has described the magnitude of effect of efficacious palliative care home-based programs, ${ }^{26,27}$ however, there has been little empirical delineation of which

\footnotetext{
${ }^{1}$ Department of Oncology, McMaster University, Hamilton, Ontario, Canada.

${ }^{2}$ Escarpment Cancer Research Institute, Hamilton, Ontario, Canada.

${ }^{3}$ Juravinski Cancer Centre, Hamilton, Ontario, Canada.

Accepted September 14, 2017.
} 
specific elements contribute to positive patient and system outcomes. ${ }^{28}$ In this article, we provide an overview of the essential components of quality palliative care in the home. Three different sources of evidence were included: descriptions of effective palliative homecare programs, perspectives of patients and caregivers, and views of healthcare providers in palliative care. Identifying the common features of palliative homecare programs associated with positive outcomes illuminates the model elements that are potentially the most impactful. The perspectives of patients and caregivers are also critical because meeting the needs of these individuals is the fundamental intent of palliative care. ${ }^{29}$ Finally, the views of providers' are important because they have broad and diverse experiences in delivering palliative care on a daily basis in multiple scenarios. Incorporating these identified components in the design of local palliative care programs will help to ensure quality care experiences for patients at end of life and their families, in an effective and cost-efficient manner.

\section{Approach}

After a rapid review (see Sims and Fassbender, this issue), we synthesized the findings of five studies that examined the key elements, either perceived or evidenced, of effective home-based palliative care, relevant to the Canadian healthcare context. These studies include a systematic review, an indepth qualitative study of palliative care programs, qualitative and quantitative perspectives of potential patients and caregivers, and qualitative perspectives of palliative care providers. An iterative and accumulative qualitative approach was used to rigorously consider the results of each study and identify the themes common to each. ${ }^{30,31}$ The analysts (H.S., D.B.) created a summary of findings and key implications for each study. The authors were involved in four of the five studies reviewed and have intimate knowledge of these data. Summary notes were compared and contrasted through discussion to derive a set of agreed common elements, represented across the studies. The findings of the original studies and the synthesized elements were vetted and discussed at an international symposium of palliative care researchers, providers, and patient advocates to ensure veracity. ${ }^{32}$

Details of each of the studies included in the synthesis are as follows:

\section{International review of the common components of efficacious palliative homecare programs}

This study reviewed all published reviews of studies of inhome programs for patients with advanced illness. ${ }^{28} \mathrm{MED}$ LINE, CINAHL, and the Cochrane Library databases were searched from 2003 to 2014 for relevant reviews. The details of every home-based program mentioned that had a significant positive effect on any outcome measured were extracted. From the 19 reviews found, 40 original studies featuring 30 unique programs were included in the component analysis. The majority of included studies were of programs in Europe $(50 \%)$ or North America (37\%). Select outcomes measured by the studies were patient quality of life, satisfaction with care, performance status, pain management and symptom management, home death rates, and reductions in healthcare use or costs. A third of the studies were randomized controlled trials, with the remainder being quasi-experimental, cohort, or prepost group designs. Among the descriptions of the homecare programs included in the review, 30 critical components emerged, ranging in prevalence from $73 \%$ to $3 \%$ of the interventions. The seven most common components were present in at least nearly half of the homecare programs reviewed.

\section{Common care practices among 11 effective community-based specialist palliative care teams}

This study involved in-depth in-person interviews with 78 providers and administrators from 11 distinct communitybased specialist palliative care teams from Ontario, Canada. ${ }^{33}$ The teams care for patients in their homes, working in conjunction with standard homecare. In a prior study, care from these specialist palliative care teams was found to be associated with a $50 \%$ reduction in late-life hospital use and hospital death, compared with usual community care. ${ }^{34}$ The interview data were collected between February and August 2013 and a qualitative thematic analysis was conducted to identify the common elements among the teams that contribute to reductions in acute care use. Core team members interviewed included the following: community nurses, personal support workers, family physicians, palliative care physicians, allied health professionals (e.g., social workers and psychosocial-spiritual counselors), specialized symptom management nurses, homecare case managers, and team managers. The teams were diverse, varying in caseload size, provider composition, and geography served. Specific care process and tools used varied among the 11 communitybased specialist palliative care teams studied. However, the teams followed a common set of seven care practices in providing care to patients and their families.

\section{Bereaved caregiver perspectives from the CaregiverVoice Survey}

Qualitative comments were extracted from the CaregiverVoice Survey completed by 628 bereaved caregivers of decedents who received homecare in Ontario. ${ }^{35,36}$ On this survey, caregivers reported what was good and bad about the care provided in the last three months of life, as well as what they would maintain or change about these services. Data were collected between September 2012 and October 2015. Of the patients represented, $26 \%$ died in the home, $65 \%$ died in a residential hospice, and $8 \%$ died in a hospital. A constant comparison method was used to derive themes from the responses, resounding what caregivers and patients most value about care at the end of life. The analysis of caregiver's opentext comments resulted in about 20 themes each of "what was positive" and "what was negative" about the homecare experience. From these themes and the caregivers' recommendations, six major values of homecare were derived.

\section{Perspectives of Canadians as to the most essential elements of a palliative homecare program}

The Canadians' Views of Palliative Care National Online Survey was conducted in August 2016 to elicit what the general public feels are the essential elements of a palliative homecare program. ${ }^{37}$ A sample of 1540 adult Canadians was surveyed, stratified by age, gender, and province of residence to be representative of the population. Survey respondents were presented with a randomized list of 15 specified service 
elements and asked to what extent they agree or disagree that each of these are essential to a palliative homecare program (four-point scale: Strongly agree to Strongly disagree). The survey found strong consensus (91\% or greater agreement) among the respondents on six elements deemed critical to palliative homecare.

\section{Perspectives of providers as to what matters most for end-of-life care}

In this study, in-person interviews were conducted with 107 frontline and administrative staff involved in palliative homecare in Ontario. ${ }^{38}$ These participants included nurses, physicians, personal support workers, spiritual and bereavement counselors, and managers, from both rural and urban settings. The respondents were prompted with the question, What matters most for end-of-life care? Interviewers followed up with probing or clarifying questions to gather deeper meanings and to explore the respondent's past experiences. Responses were analyzed using a qualitative phenomenological approach to derive themes depicting the essence of end-of-life care from the perspectives of providers. The analysis resulted in 40 unique themes, which were further grouped into 9 formulated concepts. "Fulfilling patient wishes" was the most dominant minor theme, cited by $49 \%$ of respondents. Most respondents mentioned multiple themes, with many $(21 \%)$ stating explicitly that care must embody a multifactorial approach - that focusing care exclusively on a single need, that is, pain management, is not enough to drive quality.

\section{Results}

The key elements or themes found in each individual study are presented in Table 1. Common themes were found between the five studies, representing the essential elements evidenced from the multiple different perspectives and interventions examined. From this synthesis of the findings, the six essential elements of care were found to transcend these study results (Table 1). We further describe each of these elements and the implications they have for high-quality palliative homecare.

\section{Teamwork within and across settings}

First, good homecare is inextricably linked to good care beyond settings, which includes strong linkages between different settings of hospital, homecare, primary care physicians, community agencies, and so on. This will result in smooth transitions between care settings and providers, improved communication, and better collaboration. This linkage facilitates sharing of patient information and avoids patients repeating their story over and over. Second, good homecare requires attention to building primary care capacity. This requires mechanisms for specialist palliative care providers to train and mentor generalist providers and dedicated resources for interprofessional team building and development of trusting relationships. The latter are foundational to improved processes and outcomes.

\section{Pain and symptom management}

To provide good pain and symptom management at home, the system requires a workforce where all providers have basic palliative care skills and some have specialized palliative care training and expertise, all working together in proactive planning for symptom management. Importantly, frontline homecare workers need ways to be able to consult with specialized providers when needed. Avenues to facilitate mentorship and bedside training greatly increase capacity. Currently, there is decent access to equipment in the home to address physical needs, but some barriers exist to accessing pain management medications readily (e.g., provincial drug coverage policies, access to physician to write prescriptions, and lack of access to prescriptions after-hours or delivery). ${ }^{36,39,40}$

\section{Holistic management of nonphysical and physical symptoms}

This requires attention to building and supporting interprofessional teams (including nurses, social workers, pharmacists, psycho-spiritual counselors, bereavement workers, and so on) to comprehensively address the social, mental, physical, and spiritual dimensions of dying. Having an interprofessional team can help to customize care plans and address patient's diverse needs. This holistic approach to care will result in patients feeling more at peace, resolving personal affairs, improving quality of life, and ultimately relieving all forms of suffering.

\section{Having the right people on the team}

This refers to providers who are dedicated, skilled, and compassionate and a system that supports these providers to practice in this manner. The importance of the human and relational aspects of care can be difficult to quantify but resonate strongly in qualitative assessments of quality palliative care and is integral to realizing the other essential elements. Having and sustaining the right people is a combination of selecting personnel with the appropriate disposition and skills, honing these abilities through professional development opportunities, offering adequate remuneration, and supporting these providers emotionally and otherwise in this intensive role to prevent burn-out and turnover.

\section{Timely and responsive}

The key to timely and responsive care is having access to a member of the team when crisis occurs and also educating the patient and family to know what to do during crises (alongside proactive symptom management). Having access to a member of the care team 24/7 is ideal; however, having some extended hours (e.g., 7 am-9 pm) with clear instructions for families to know what to do in crises during off-hours is also effective. This will result in timely response of exacerbations, avoidance of unnecessary hospitalizations, and ultimately, patients and families always feeling supported and not alone. In addition, providing timely care includes early identification of those who can benefit from a palliative care approach. In other words, not waiting until death is imminent to initiate palliative care.

\section{Patient and family preparedness}

Supporting the patient and the family as one unit is important to providing high-quality palliative care. This requires education and guidance to the patients and families 


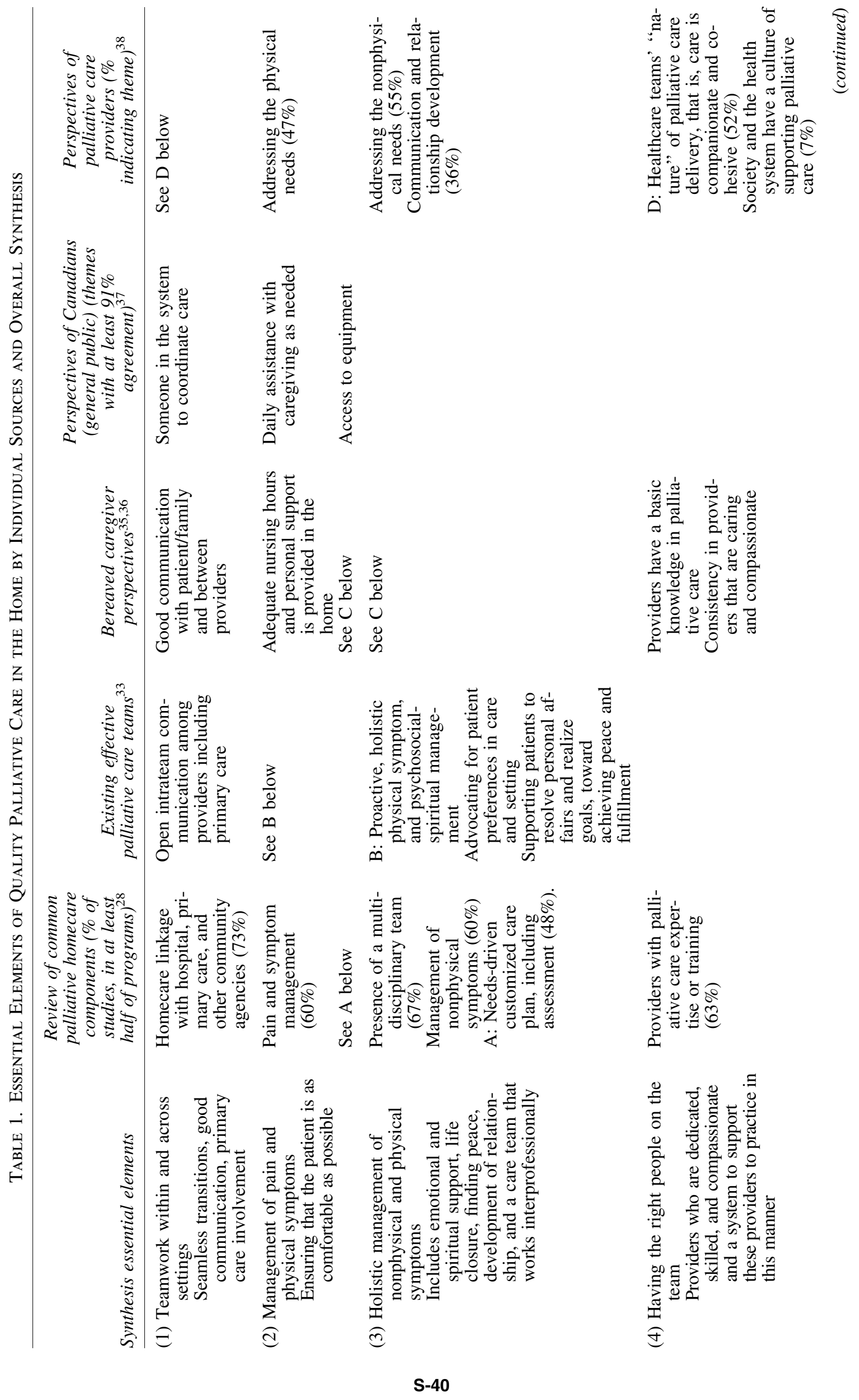




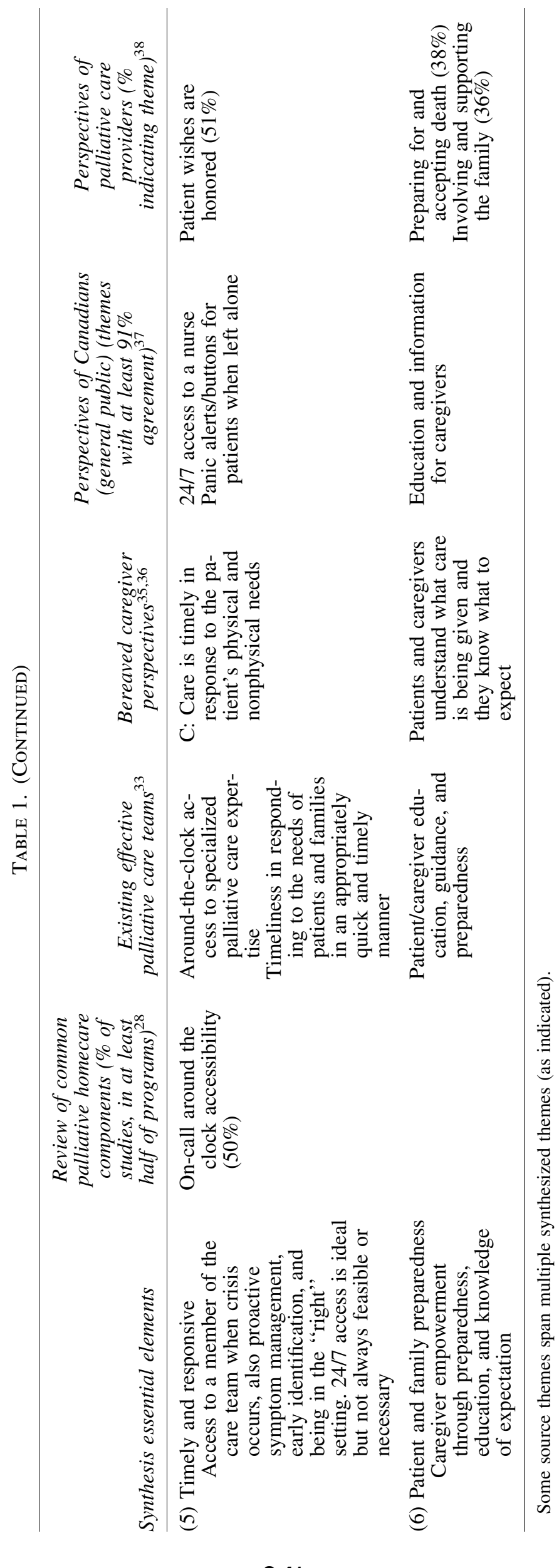


about what to expect as function declines and disease progresses. This also involves clarity on care expectations and service limitations. Palliative care patients and families can be empowered with knowledge, and become active contributors to care provision, if desired. Moreover supporting families means adequate caregiver respite and assistance with caregiving.

\section{Discussion}

In this overview, we synthesized the six essential elements of quality palliative homecare based on evidence of program components associated with positive patient and system outcomes, as well as, the perspectives of patients, caregivers, and healthcare providers. Palliative care in the home, and often in general, must use an integrated team approach and involve the right compliment of providers to holistically manage physical and nonphysical symptoms, be responsive to patients' needs in a timely manner, and proactively prepare the patient and family for the end-of-life trajectory. These findings are supported by the international research. $^{41,42}$

In considering these elements in the development of palliative homecare services, it is important to remember that local context matters. Although the real-life examples examined in this review shared many common care principles, no two programs were identical. ${ }^{28,33}$ Rather, each model reflects local community partnerships, culture, and assets. Obtaining integration of community-based services is a challenge, particularly in palliative care where multiple providers and organizations may be involved. ${ }^{43}$ A demonstrated approach to achieving the essential elements proposed is to start small and build on local strengths. ${ }^{33,44,45}$ Evidence shows that a top-down, one-size-fits-all approach often fails in implementing and sustaining quality palliative care programs. ${ }^{33,46}$ Recommendations cannot be too rigid in terms of structures and processes. The essential elements of quality palliative care as indicated should be standardized, but how to achieve them should be flexible. For instance, a chart in the home is only one strategy to improve linkage and communication, but is not the only solution or one that will always work. A panic button for patients to push in immediate need is one means to achieve timely responsiveness, but there may be a more effective ways based on existing local structures. Ultimately, solutions need to be derived from the local context and local providers.

There are limitations to this review. We only considered select literature, although the studies represented are among a few that capture the different perspectives examined toward palliative homecare in a rigorous manner. Furthermore, four of the studies represent either perceptions or interventions from Canada that may not have broad applicability to different healthcare systems. ${ }^{33,35-38}$ However, the themes in the original studies were found to correspond to similar studies from other countries, which also share similarities with the systematic review of international programs included in the synthesis. ${ }^{28,41,42}$ For example, a multisetting study in France of the specified elements of palliative care important to patients, caregivers, and providers, found four broad critical dimensions that largely correspond to our essential elements: comprehensive support; management of pain and other symptoms; involvement of families, including clear communication; and the care provided to the imminently dying person, including respecting patient preferences. ${ }^{47}$ Finally, each of the studies we reviewed has its own inherent limitations, previously described in its respective publication. . $^{28,33,35-38}$

\section{Conclusion}

Six essential elements of palliative homecare programs evolved from our rapid review and research synthesis. These elements correspond to the broader findings of prior international research and the constituents of palliative care best practice exercised in many countries. ${ }^{48}$ Our delineation of these elements is unique in being empirically based on the formative examination of existing successful palliative homecare programs as well as the perceptions of those using and providing these services. Developing and resourcing palliative homecare programs that embody these elements play a critical role in ensuring a positive experience for patients and families at end of life.

\section{Author Disclosure Statement}

No competing financial interests exist.

The study was approved by Hamilton Health Sciences/ McMaster University Research Ethics Review Board, Ontario, Canada.

\section{References}

1. Gomes B, Calanzani N, Gysels M, et al.: Heterogeneity and changes in preferences for dying at home: A systematic review. BMC Palliat Care 2013;12:7.

2. Rice DP, Fineman N: Economic implications of increased longevity in the United States. Annu Rev Public Health 2004;25:457-473.

3. Spillman BC, Lubitz J: The effect of longevity on spending for acute and long-term care. N Engl J Med 2000;342: 1409-1415.

4. Bainbridge D, Seow H, Sussman J, et al.: Factors associated with not receiving homecare, end-of-life homecare, or early homecare referral among cancer decedents: A population-based cohort study. Health Policy 2015;119: 831-839.

5. Centers for Medicare \& Medicaid Services. Medicare hospice benefits. Baltimore: U.S. Department of Health and Human Services. 2017. www.medicare.gov/Pubs/pdf/ 02154-Medicare-Hospice-Benefits.PDF (Last accessed June 12, 2017).

6. United States General Accounting Office. More Beneficiaries Use Hospice But for Fewer Days of Care. Washington, DC: GAO, 2011.

7. World Health Organization. Home Care in Europe. Denmark: WHO, 2008.

8. Hearn J, Higginson IJ: Do specialist palliative care teams improve outcomes for cancer patients? A systematic literature review. Palliat Med 1998;12:317-332.

9. Higginson IJ, Finlay IG, Goodwin DM, et al.: Is there evidence that palliative care teams alter end-of-life experiences of patients and their caregivers? J Pain Symptom Manage 2003;25:150-168.

10. Higginson IJ, Evans CJ: What is the evidence that palliative care teams improve outcomes for cancer patients and their families? Cancer J 2010;16:423-435. 
11. Aiken LS, Butner J, Lockhart CA, et al.: Outcome evaluation of a randomized trial of the PhoenixCare intervention: Program of case management and coordinated care for the seriously chronically ill. J Palliat Med 2006;9:111-126.

12. Bakitas M, Lyons KD, Hegel MT, et al.: Effects of a palliative care intervention on clinical outcomes in patients with advanced cancer: The Project ENABLE II randomized controlled trial. JAMA 2009;302:741-749.

13. Brumley R, Enguidanos S, Jamison P, et al.: Increased satisfaction with care and lower costs: Results of a randomized trial of in-home palliative care. J Am Geriatr Soc 2007;55:993-1000.

14. Hughes SL, Cummings J, Weaver F, et al.: A randomized trial of the cost effectiveness of VA hospital-based home care for the terminally ill. Health Serv Res 1992;26:801817.

15. Hughes SL, Weaver FM, Giobbie-Hurder A, et al.: Effectiveness of team-managed home-based primary care: A randomized multicenter trial. JAMA 2000;284:2877-2885.

16. Rabow MW, Dibble SL, Pantilat SZ, McPhee SJ: The comprehensive care team: A controlled trial of outpatient palliative medicine consultation. Arch Intern Med 2004; 164:83-91.

17. Zimmer JG, Groth-Juncker A, McCusker J: A randomized controlled study of a home health care team. Am J Public Health 1985;75:134-141.

18. Higginson IJ, McCrone P, Hart SR, et al.: Is short-term palliative care cost-effective in multiple sclerosis? A randomized phase II trial. J Pain Symptom Manage 2009;38: 816-826.

19. Ahlner-Elmqvist M, Jordhoy MS, Jannert M, et al.: Place of death: Hospital-based advanced home care versus conventional care. A prospective study in palliative cancer care. Palliat Med 2004;18:585-593.

20. Fukui S, Kawagoe H, Masako S, et al.: Determinants of the place of death among terminally ill cancer patients under home hospice care in Japan. Palliat Med 2003;17:445-453.

21. McWhinney IR, Bass MJ, Orr V: Factors associated with location of death (home or hospital) of patients referred to a palliative care team. CMAJ 1995;152:361-367.

22. Miccinesi G, Crocetti E, Morino P, et al.: Palliative home care reduces time spent in hospital wards: A populationbased study in the Tuscany Region, Italy. Cancer Causes Control 2003;14:971-977.

23. Serra-Prat M, Gallo P, Picaza JM: Home palliative care as a cost-saving alternative: Evidence from Catalonia. Palliat Med 2001;15:271-278.

24. Sessa C, Roggero E, Pampallona S, et al.: The last 3 months of life of cancer patients: Medical aspects and role of homecare services in southern Switzerland. Support Care Cancer 1996;4:180-185.

25. Vinciguerra V, Degnan TJ, Sciortino A, et al.: A comparative assessment of home versus hospital comprehensive treatment for advanced cancer patients. J Clin Oncol 1986; 4:1521-1528.

26. Luckett T, Davidson PM, Lam L, et al.: Do community specialist palliative care services that provide home nursing increase rates of home death for people with life-limiting illnesses? A systematic review and meta-analysis of comparative studies. J Pain Symptom Manage 2013;45:279297.

27. Muller C, Lautenschlager S, Meyer G, Stephan A.: Interventions to support people with dementia and their caregivers during the transition from home care to nursing home care: A systematic review. Int J Nurs Stud 2017;71: 139-152.

28. Bainbridge D, Seow H, Sussman J: Common components of efficacious in-home end-of-life care programs: A review of systematic reviews. J Am Geriatr Soc 2016;64: 632-639.

29. Bainbridge D, Brazil K, Krueger P, et al.: A proposed systems approach to the evaluation of integrated palliative care. BMC Palliat Care 2010;9:8.

30. Pope C, Ziebland S, Mays N: Qualitative research in health care. Analysing qualitative data. BMJ 2000;320:114-116.

31. Walsh D, Downe S: Meta-synthesis method for qualitative research: A literature review. J Adv Nurs 2005;50:204-211.

32. Palliative Care Matters. Consensus development conference program. 2017. www.palliativecarematters.ca/program (Last accessed June 12, 2017).

33. Seow H, Bainbridge D, Brouwers M, et al.: Common care practices among effective community-based specialist palliative care teams: A qualitative study. BMJ Support Palliat Care 2017 [Epub ahead of print].

34. Seow H, Brazil K, Sussman J, et al.: Impact of community based, specialist palliative care teams on hospitalisations and emergency department visits late in life and hospital deaths: A pooled analysis. BMJ 2014;348:g3496.

35. Bainbridge D, Giruparajah M, Zou H, Seow H: The care experiences of patients who die in residential hospice: A qualitative analysis of the last three months of life. Palliat Support Care 2017.

36. Bainbridge D, Bryant D, Seow H: Capturing the palliative home care experience from bereaved caregivers through qualitative survey data: Toward informing quality improvement. J Pain Symptom Manage 2017;53:188-197.

37. Roulston E: Canadians' Views of Palliative Care National Online Survey. 2017. Ipsos. www.cspcp.ca/wp-content/ uploads/2016/09/Palliative-Care-Matters-Ipsos-Report.pdf (Last accessed June 12, 2017).

38. Mistry B, Bainbridge D, Bryant D, et al.: What matters most for end-of-life care? Perspectives from communitybased palliative care providers and administrators. BMJ Open 2015;5:e007492.

39. Holland JM, Keene JR, Kirkendall A, Luna N: Family evaluation of hospice care: Examining direct and indirect associations with overall satisfaction and caregiver confidence. Palliat Support Care 2015;13:901-908.

40. Office for National Statistics (ONS): Statistical bulletin: National Survey of Bereaved People (VOICES): England, 2015. 2015. London, UK, ONS. www.ons.gov .uk/peoplepopulationandcommunity/healthandsocialcare/ healthcaresystem/bulletins/nationalsurveyofbereavedpeoplevoices/ england2015 (Last accessed June 12, 2017).

41. Black J: What are patients' priorities when facing the end of life? A critical review. Int J Palliat Nurs 2011;17:294300 .

42. Ventura AD, Burney S, Brooker J, et al.: Home-based palliative care: A systematic literature review of the selfreported unmet needs of patients and carers. Palliat Med 2014;28:391-402.

43. Bainbridge D, Brazil K, Ploeg J, et al.: Measuring healthcare integration: Operationalization of a framework for a systems evaluation of palliative care structures, processes, and outcomes. Palliat Med 2016;30:567-579.

44. Graham ID, Logan J, Harrison MB, et al.: Lost in knowledge translation: Time for a map? J Contin Educ Health Prof 2006;26:13-24. 
45. Kelley ML, Williams A, DeMiglio L, Mettam H: Developing rural palliative care: Validating a conceptual model. Rural Remote Health 2011;11:1717.

46. Kodner DL: All together now: A conceptual exploration of integrated care. Healthc Q 2009;13 Spec No:6-15.

47. Vedel I, Ghadi V, Lapointe L, et al.: Patients', family caregivers', and professionals' perspectives on quality of palliative care: A qualitative study. Palliat Med 2014;28: 1128-1138.

48. Barazzetti G, Borreani C, Miccinesi G, Toscani F: What "best practice" could be in palliative care: An analysis of statements on practice and ethics expressed by the main Health Organizations. BMC Palliat Care 2010;9:1.

Address correspondence to: Hsien Seow, PhD Department of Oncology McMaster University 699 Concession Street, Room 4-229

Hamilton, Ontario L8V $5 C 2$

Canada

E-mail: seowh@mcmaster.ca 